\title{
ПЕДАГОГИЧЕСКИЕ НАУКИ
}

\section{ОСНОВНЫЕ ЭТАПЫ РАБОТЫ НАД МУЗЫКАЛЬНЫМ ПРОИЗВЕДЕНИЕМ}

Гольдфайн Леонид Аркадьевич

(Россия, г. Москва)

дочент кафедры музыкально-исполнительского искусства

Института изящных искусств

ФГБОУ ВО «Московский Педагогический Государственный Университет».

\section{MAJOR STEPS OF PIECE OF MUSIC DEVELOPMENT}

\author{
Goldfayn Leonid Arkadjevich \\ (Moscow, Russia) \\ Associate Professor, \\ Musical and Performing Arts Department, \\ Institute of Fine Arts, \\ Moscow State Pedagogical University. \\ DOI: 10.31618/nas.2413-5291.2020.1.55.214
}

\section{Аннотация}

В настоящей статье рассматриваются основные моменты работы над музыкальным произведением. Автор разделяет процесс изучения на три этапа: первый - ознакомительный, второй - детальная работа над произведением, третий - завершающий, подготавливающий произведение к публичному исполнению.

Особое внимание уделяется работе педагога в ДМШ, так как обучаемые обладают разной степенью одаренности и, укладываясь в жесткую норму по времени занятий, преподаватель должен прививать и развивать у учащихся сложнейшие исполнительские навыки. В работе с учеником педагог-музыкант должен не только следить за технически точным исполнением произведения, но и неустанно акцентировать внимание на художественности и выразительности музыкального материала, а также развивать творческий подход учащегося к прочтению и способам овладения нотного текста.

\section{Abstract}

This article discusses the main points of musical composition development. The author divides the study process into three stages: the first - introductory, the second - detailed work on the piece, the third - final, preparation for public performance.

Special attention is paid to work of teacher in the DMSH, since students are differently gifted and yet teacher is expected to instill and develop students ' most complex performing skills while staying withing rigid time limits. When working with students, tutor musician should not only monitor the technically accurate performance of the work, but also constantly focus on the artistry and expressiveness of the musical material, as well as develop the student's creative approach to reading and mastering the musical text.

Ключевые слова. Музыкальное произведение, основные этапы работы, педагог-музыкант, ученик, ДМШ, исполнительские навыки, одаренность, творческий подход, профессиональная работа.

Keywords. Musical composition, main stages of work, teacher-musician, student, DMSH, performing skills, giftedness, creativity, professional work.

Как известно, работа педагога в детской музыкальной школе (школе искусств) очень сложна и многогранна., так как он постоянно сталкивается с учениками различной степени одаренности и, укладываясь в жесткие временные рамки, ему приходится обучать своих воспитанников постигать сложнейшие исполнительские навыки. Для этого преподаватель должен обладать не только глубочайшими знаниями, но и владеть высокой техникой педагогической работы, то есть найти подход к каждому ученику, учитывать его индивидуальные особенности, уметь правильно спланировать урок, чтобы успеть проверить домашнее задание и дать конкретные указания для дальнейшего изучения данного произведения.

От нас, педагогов, требуется научить своего подопечного глубоко проникать в художественный замысел произведения на основе вдумчивого прочтения нотного текста, поэтому с первых шагов изучения конкретного музыкального материала необходимо познакомить ученика со стилевыми и жанровыми особенностями произведения, а также с той исторической эпохой, в которой жил и творил композитор. Очень хотелось бы, чтобы указания педагога встречали эмоциональный отклик у ученика, но здесь важно заметить, что нельзя подвергать скептицизму ту трактовку произведения, которую может предложить ребенок. А чтобы как-то расшевелить детское воображение, необходимо играть ученику яркие интересные произведения, которые будут доступны его сознанию, уметь образно раскрывать средства, которыми воспользовался композитор, чтобы донести содержание произведения до слушателя.

Итак, что же включает в себя работа над музыкальным произведением? На наш взгляд, это прежде всего «вживание» в мир музыкальноэмоциональных образов и постепенное формирование у ученика конкретного исполнительского замысла. 
Но сразу надо сказать, что эта работа не должна быть форсированной. «Не надо на каждом уроке, на каждой пьесе научить всему на свете. У нас мудрят, дают миллион указаний и в результате запутывают ученика» [1, с.23].

Теперь более подробно рассмотрим основные эmanb работы над музыкальным произведением.

Первый этап, который включает в себя непосредственное ознакомление с произведением. Для этого педагогу рекомендуется самому его исполнить или, если произведение более «взрослое», то дать послушать его в аудио или видеозаписи. Желательно при этом следить за текстом по нотам.

Далее следует определить характер и строение произведения, рассмотреть тональный план, штрихи, динамику, наметить кульминационные точки и основные технические приемы, которые будут использоваться в работе.

Хотелось бы услышать от ученика о его впечатлениях о прослушенной музыке. Было бы желательно предложить ему дома самому прочитать биографию композитора, а также, что не менее важно, послушать другие произведения исполняемого автора.

Второй этап, который идет после ознакомления с произведением, это разбор, который включает в себя тщательное прочтение и осмысливание всех нотных обозначений. Преподаватель должен заранее отредактировать текст, проставить в нужных местах аппликатуру, уточнить редакцию (особенно в полифонических произведениях) и т.д.

Нужно учитывать, что сложность процесса разбора прежде всего заключается в том, что учащемуся необходимо распределять внимание на множество «объектов» - знаки, ритм, артикуляция, педализация, пальцы и др.

По времени это наиболее протяженный период работы, совпадающий с так называемым «техническим» освоением музыкального материала. В раскрытии же художественного содержания произведения первостепенную роль будет играть, как мы уже подчеркивали, грамотный и всесторонний его анализ. «Лишь тогда, когда станет ясной форма, будет ясным и содержание»,говорил Р.Шуман [5,с.182].

На этом этапе очень важно тщательное проигрывание в замедленном темпе, чтобы успевать проследить за всеми встречающимися указаниями. Так, Э.Гилельс советовал все медленные произведения играть еще медленнее, а Г.Нейгауз даже с преувеличенными оттенками, ибо только в такой работе исполнитель сможет добиться тщательности во всех деталях, успеет проследить за постановкой рук, при которой можно добиться нужного звукоизвлечения.

Параллельно ведется работа над выразительностью, раскрытием содержания, фразировкой и динамикой. Одновременно идет и запоминание наизусть. Полезно найти так называемые «точки опоры», разделить произведение на более мелкие части и работать по ним.
Конечно, разучивание произведения с учеником - работа сложная для педагога. При этом «он должен быть одновременно и историком музыки, и теоретиком, учителем сольфеджио, гармонии, контрапункта и игры на фортепиано» [3, c.194].

Заметим, что правомерны различные трактовки произведения. Важно только, чтобы это было на основе тщательного изучения авторского текста, а для этого важно воспитывать у обучаемых умение замечать и осмысливать все обозначения, имеющиеся в нотном тексте.

Следует остановиться на таком важном аспекте, как выучивание произведения наизусть. Педагог может решить по-разному, когда надо начинать учить данное произведение на память, то есть, в начале разучивания, а потом уже отрабатывать технически, или наоборот. Единого мнения на эту проблему нет, но практика показывает, что выучивание наизусть все-таки в большинстве случаев должно проходить на этапе, когда ученик уже достаточно уверенно овладел нотным текстом.

Известно много вариантов заучивания наизусть, но, на наш взгляд, наиболее эффективен следующий: выученное на память произведение исполняется в медленном темпе с детальным вслушиванием и осознанием конкретного текста.

Хотелось бы вспомнить метод, который предложил И.Гофман. Он пишет, что «Существуют четыре способа разучивания произведения:

- за фортепиано с нотами;

- без фортепиано с нотами;

- за фортепиано без нот;

- без фортепиано и без нот.

Второй и четвертый способы, без сомнения, наиболее трудны и утомительны в умственном отношении; но зато они лучше способствуют развитию памяти» [2, с.133].

Как опять же показывает практика, самым распространенным и применяемым будет первый способ. Рекомендуется разделить произведение на части или эпизоды и работать поэтапно, постепенно добиваясь нужного качественного результата.

Можно порекомендовать и некоторые другие способы запоминания и последующего выучивания произведения наизусть. Например,

- поучить отдельно партию каждой руки или каждого голоса (в полифонических произведениях) наизусть, что даст обучаемому возможность лучше услышать и затем запомнить каждый голос в отдельности и далее охватить всю фактуру.

-уметь сыграть произведение с любого раздела или части, что в дальнейшем, безусловно, приведет к большей внутренней уверенности при исполнении;

- можно идти с конца произведения, то есть пытаться исполнить произведение на память с последнего предложения и затем в обратном порядке прибавлять по одной фразе.

При данном методе работы, ученик в определенной степени может быть «гарантирован» от случайностей на публичном выступлении, так как в этом случае он сможет охватить не только 
произведение в целом, но и представить себе любое конкретное построение.

Не менее важной, на наш взгляд, считается работа над звуком. И одна из важнейших задач достижения качественного звукоизвлечения - это умение вслушиваться в звучание инструмента, добиваясь от ученика естественной и мягкой окраски звука.

Г. Нейгауз рассказывает, как один молодой артист был выслушан очень крупным мэтром. Он прочел монолог Гамлета, стихи Пушкина и что-то еще. Маститый актер сказал, что это очень хорошо, а теперь надо попробовать 17 раз сказать «А» $\mathrm{c}$ разными оттенками: «А -восхищения», «Авопросительное», «А-угрожающее» и т.д. «Вот это я имею ввиду, когда утверждаю, что взять один единственный звук одним пальцем на фортепиано - уже задача, притом задача интересная и важная в познавательном отношении». [3, с.134].

А известный пианист и педагог Н.Перельман очень образно характеризует оттенки звука: они обладают «вкусом, цветом, объемом, красотой или уродством, силой, весом, длиной и всем, чем только способен наделить его обладающий фантазией музыкант... Музыкант говорит о звуке, как о фрукте - сочный, густой, мягкий, нежный; как о чем-то зримом - светлый, тусклый, солнечный, блеклый, белый; как о предмете... - круглый, плоский, глубокий, мелкий, тяжелый, легкий, длинный, короткий. Звуку приписывают даже нравственные категории: благородный... Звук должен быть и умным... [4, с.8].

Нельзя не сказать о такой важной проблеме, как педализация, которая необходима при работе над выработкой певучего звука. Ученику следует рассказать о важных качествах педали и говорить о новой (тембровой) окраске звука., а также о связывании звуков и аккордов, объединении гармонической фигурации.

Элементарная техника педализации - мягкое, незаметное нажатие и смена педали, точное согласование действий ноги и руки под «управлением» слуха. Главное при работе над педализацией помнить, что ученик должен хорошо себя слушать и при исполнении произведения исходить из музыкального образа, стараться глубоко раскрыть содержание.

«Одна из главных задач педали - это лишить фортепиано некоторой доли сухости и непродолжительности звука, которая так невыгодно отличает его от всех других инструментов. Поэтому, играя одноголосую мелодическую фразу в медленном темпе (без всякого аккомпанемента), вы вправе пользоваться педалью на каждой ноте мелодии, чтобы придать ей больше певучести и более богатую тембровую окраску» [3, с.176].

$\mathrm{He}$ менее важной стороной является техническое овладение произведением. Здесь можно говорить о двух основных моментах: преодоление технических сложностей в умеренном темпе и работа над определенными техническими приемами в необходимом для данного произведения характере звучания и в конечном темпе.
Как мы уже указывали ранее, все технические трудности следует отрабатывать в медленном темпе до тех пор, пока они не будут доведены до автоматизма; желательно прорабатывать трудные места отдельными руками, а особо трудные пассажи разделить на небольшие «отрезки» и последовательно осваивать в медленном темпе.

Чтобы хорошо развить технические возможности обучаемых, безусловно, надо тренировать пальцы, но очень много в этом процессе будет зависеть от головы. И как показывает многолетняя практика работы с детьми (и не только с детьми!) - многие из них обладают неплохой беглостью, но при этом пальцы двигаются механически, то есть без включения мыслительных функций. И в этом случае исполнение становится бездушным и абсолютно формальным проигрыванием...

Третий этап работы над музыкальным произведением должен показать, что ученик может сыграть все выученное наизусть, при этом достаточно грамотно стилистически и технически точно. На этом этапе важно формирование и в дальнейшем реализация целостного художественного замысла, который опять же будет связан с технической точностью, «совершенством» исполнения и определенной уверенностью в себе.

Здесь очень будет важна работа над выразительностью, раскрытием содержания, фразировкой, динамикой и т.д.

Следует заметить, что правомерны различные истолкования произведения. Важно только, чтобы это было на основе тщательного изучения авторского текста, а для этого необходимо воспитывать у обучаемых умение замечать и осмысливать все обозначения, которые имеются в нотном тексте.

Когда все подготовительные стадии работы над произведением будут пройдены, то наступает основной момент - «вынос» произведения на публику. И этот момент очень ответственный, так как у многих учеников нет необходимого чувства эстрады. Мы-педагоги должны систематически работать над развитием этого чувства, но подходить к этому тактично и разумно (например, ни в коем случае нельзя делать замечания ученику во время выступления!).

«Публичная игра не только хороший стимул к дальнейшим успехам; она еще дает весьма точную оценку ваших способностей и недостатков и тем самым указывает путь к совершенствованию» $[2$, c.179].

В заключении необходимо еще раз напомнить ,что работа педагога должна быть высокопрофессиональной и, что к каждому ученику должен быть индивидуальный творческий подход.

\section{Литература:}

1.Гольденвейзер. А. «Вопросы фортепианной педагогики», М., «Музыка»,1967, 290с.

2.Гофман И. Фортепианная игра. Ответы на вопросы о фортепианной игре. М., Музгиз, 1961, $224 c$. 
3.Нейгауз Г. «Об искусстве фортепианной игры. Записки педагога» М., «Музыка»,1967, 322с.

4. Перельман Н. В классе рояля «Музыка», Лд, 1970, 56c.

\section{ИСПОЛЬЗОВАНИЕ ЧЕК-ЛИСТОВ КАК ИНСТРУМЕНТА ВИЗУАЛЬНОЙ ПОДДЕРЖКИ В РАЗВИТИИ ДЕЯТЕЛЬНОСТИ ПОДРОСТКОВ С РАССТРОЙСТВАМИ АУТИСТИЧЕСКОГО СПЕКТРА}

\author{
Гусева Надежда Юрьевна \\ кандидат психологических наук, руководитель \\ регионального ресурсного иентра по организачии \\ сопровождения детей с РАС, ГБУДО НО «ЦППМСП»
}

г. Нижний Новгород

\title{
USING CHECKLISTS AS A VISUAL SUPPORT TOOL IN THE DEVELOPMENT OF ACTIVITIES OF ADOLESCENTS WITH AUTISM SPECTRUM DISORDERS
}

\author{
Guseva Nadezhda \\ candidate of psychological sciences, head of the \\ Regional Resource Center for Supporting Children with ASD. \\ State-Funded Institution of Supplementary Education \\ Nizhny Novgorod \\ DOI: 10.31618/nas.2413-5291.2020.1.55.210
}

\section{Аннотация}

В данной статье рассматривается некоторые аспекты применения чек-листов как инструмента визуальной поддержки деятельности подростков с РАС. Анализируются основные причины, по которым данный вид визуальной поддержки является наиболее эффективным в реализации продуктивной деятельности обучающихся данной категории.

\section{Abstract}

This article discusses some aspects of using checklists as a tool for visual support of the activities of adolescents with ASD. The main reasons why this type of visual support is the most effective in the implementation of productive activities of students in this category are analyzed.

Ключевые слова: расстройства аутистического спектра; визуальная поддержка; чек-листы; продуктивная деятельность.

Keywords: autism spectrum disorders; visual support; checklists; productive activity.

Визуальная поддержка является наиболее эффективным способом организации деятельности ребенка с РАС. Данный вопрос является одним из самых методически разработанных аспектов в адаптации учебных материалов и социальной среды детей данной категории $[1,3,5]$. Визуальная поддержка сопровождает самые эффективные методы альтернативной коммуникации, визуальных расписаний и визуальных подсказок, используемых в формировании новых навыков [4]. Поскольку сфера визуального восприятия, внимания и памяти у большинства детей с РАС развита достаточно хорошо, по сравнению с аудиальной, данные методы позволяют ребенку быстро приобретать коммуникативные, социальнобытовые и академические навыки. Тем не менее, при эффективной коррекции, начатой в раннем возрасте, ребенок с РАС со временем перерастает даже самые универсальные методики. Очень часто подросток обладает большим количеством компетенций благодаря длительному использованию визуальной поддержки: навыки коммуникации, беглое чтение, определенный уровень академических навыков, быстрая ориентировка в визуально представленных дидактических материалах, таких как конструкторы, паззлы и т.д. Тем не менее, возрастные изменения и социальная среда требуют от него перехода к новым, более взрослым видам деятельности, которые неизменно требуют организации визуальной поддержки. Данный вопрос все еще требует научной и методической проработки в связи с разнообразием интересов и возможностей в деятельности подростков с РАС.

Известно, что аутизм проявляется не только в своих непосредственных дефицитах: нарушении коммуникации и социального взаимодействия, но также сопровождается рядом сложностей, связанных с организацией деятельности. Таким образом, даже для подростка с РАС, обладающего большим количеством навыков, с большой вероятностью нужна помощь в освоении новых видов деятельности. Основные трудности в освоении новой деятельности для людей с РАС обусловлены дефицитами слухового восприятия и удержания инструкции на слух, а также планирования, контроля и оценки результатов собственной деятельности. Данные преграды мы постарались максимально нивелировать в организации деятельности подростков с РАС.

С целью формирования навыков планирования и самоконтроля в продуктивной деятельности подростков с РАC в региональном ресурсном центре по организации сопровождения детей с РАC была разработана программа дополнительного образования по направлению декоративно- 